Article

\title{
Experiences of unemployment and well-being after job loss during economic recession: Results of a qualitative study in east central Sweden
}

\author{
Anne-Sofie Hiswåls, ${ }^{1,2}$ Anneli Marttila, ${ }^{3}$ Emelie Mälstam, ${ }^{2}$ Gloria Macassa ${ }^{1-4}$ \\ ${ }^{1}$ Department of Health Sciences, Section of Public Health Sciences, Mid-Sweden University, \\ Sweden; ${ }^{2}$ Department of Occupational and Public Health Science, University of Gävle, Sweden; \\ ${ }^{3}$ Department of Public Health Sciences, Karolinska Institutet, Stockholm, Sweden; ${ }^{4}$ Epidemiology \\ Unit-ISPUP, University of Porto Medical School, Portugal
}

\begin{abstract}
Significance for public health
The most recent economic recession, which started in 2008, raised major concerns that it would negatively affect population health. This article describes and discuss the experiences of unemployment and well-being among individuals who lost their job due to the economic recession in Gävle Municipality. The significance of the article is that it shows how central it is to get a better understanding of the experiences of hardship and perceptions of health and overall well-being among people who lost their work involuntarily. Findings of this study can be used to inform policy makers as well as provide guidance for health promotion activities among groups who are prone to unemployment. Furthermore results of the study can be of interest to similar geographic contexts.
\end{abstract}

\section{Abstract}

Introduction: Several studies have revealed an association between unemployment and ill health, and shown that unemployment can affect people differently. This study aimed to provide an understanding of the experiences of unemployment and perceptions of wellbeing among persons who involuntary lost their work during the recent economic recession in Gävle Municipality.

Methods: Sixteen unemployed men and women aged 28-62 were interviewed face-to-face. A purposeful sampling strategy was used in order to suit the research question and to increase the variation among informants. The interview texts were analysed using thematic analysis.

Results: Six different themes emerged from the accounts: The respondents perceived work as the basis for belonging, and loss of work affected their social life and consumption patterns due to changes in their financial situation. They also expressed feelings of isolation, loss of self-esteem, and feelings of hopelessness, which affected their physical well-being. Longer duration of unemployment increased the respondents' negative emotions. The respondents reported activities, structure, and affiliation in other contexts as part of their coping strategy against poor mental health.

Conclusions: After job loss, the respondents experienced feelings of loss of dignity and belonging as a human being. They also felt worry, insecurity, and stress due to their changed financial situation, which in turn led to isolation and loss of self-esteem. Social support and having other activities gave the respondents structure and meaning.

\section{Introduction}

Employment is one of the factors used to describe the economic and social situation in different countries, especially during economic recession. It is also considered the main source of private economic resources, and thereby enables economic participation in society and is a source of social identity in society where work is the norm. Given these needs for employment, unemployment is considered to impact mental well-being. ${ }^{1}$ For instance, Giuntoli et al. ${ }^{2,3}$ found mental well-being to be affected by financial strain. The authors also found experiences of loss of their role in the society, loss of time structure, and motivation, as well as personal identity crises among participants. Such psychosocial functions, as time structure, social contact, status and identity are also used to explain the health consequences of unemployment in the latent functions model developed by Jahoda.,5 Moreover, Huffman et al. found among unemployed within a single state in the south-western United States, latent benefits (collective purpose, social contact, status, time structure, enforced activity) being more related to psychological well-being in those with greater financial strain. ${ }^{6}$ However, there is still debate over whether the relationship between unemployment and ill health is a causal one. Studies investigating the impact of plant closures and mass layoffs as exogenous entries to unemployment have shown support for both causal $^{7,8}$ and non-causal ${ }^{9,10}$ associations between unemployment and ill health.

Additionally, several studies have revealed an association between unemployment and damaging health behaviour, such as smoking and drinking problems. ${ }^{11-16}$ For instance, in a follow-up cohort of students from elementary school, where employment status was assessed every six months and health status at the age of thirty, Virtanen et al. found a significant association between prolonged unemployment and risky alcohol consumption and smoking. 16

Previous research indicates that unemployment might associate with health in different ways, and studies from different countries have also shown that this effect varies between groups. ${ }^{15,17-21}$ For instance, Artazcoz et al. found that the consequences of unemployment on mental health are unequally distributed across groups with different social class, family roles, and gender. ${ }^{17}$ In a literature review of job loss and job search experiences for mature-aged workers, Kira et al. found that loss of work disrupts continuity and control of selfhood. ${ }^{21}$ In a Chinese study with face-to-face interviews, subjective well-being was found to increase with socioeconomic status such as income and education and to be lower among unemployed individuals. ${ }^{20}$ Furthermore, a qualitative study by Björklund et al. found that among Finish men, unem- 
ployment produced feelings of worry, guilt, shame, and exclusion from society. ${ }^{22}$ Similar results were found by Patton and Donohue, who used a mixed method involving in-depth interviews and a brief quantitative questionnaire among 38 long-term unemployed men and women attending employment training for long-term unemployed people in Australia. ${ }^{23}$ The respondents described experience of financial difficulties, lack of social contact, feelings of guilt, loss of confidence, diminishing motivation, and treatment of depression. ${ }^{23}$ Furthermore, even when the individuals could recognise themselves as using coping strategies, they considered these strategies short-term or ineffective. ${ }^{23}$

The concept of wellbeing has traditionally been associated with the discipline of psychology were the greatest emphasis is given to mental well-being (mental disorders). However, in recent years, well-being has become a topic for research across several scientific disciplines, including public health and health sciences. $^{24-27}$ The association of well-being with physical and mental health and its strong value across major domains in life are suggested to be the driving force behind this broad interest. ${ }^{25}$ For instance, a study in the UK of the social determinants of subjective wellbeing, found socio-demographic characteristics such as age, gender, ethnicity, household composition, employment and health status, all mattered for well-being. ${ }^{27}$ Moreover, terms like wellbeing, satisfaction with life, happiness, or quality of life are often used interchangeably. ${ }^{28}$ In our study well-being is defined as overall physical and psychological well-being including perceptions of quality of life.

However, so far, the associations between unemployment and ill health have been investigated to a greater extent by quantitative than qualitative studies; and, according to Giatti et al., quantitative studies alone have limitations when it comes to discerning shades of complex issues associated with people in different contexts. ${ }^{29}$

The most recent economic recession, which started in 2008 , raised major concerns that it would negatively affect public health and contribute to, for example, mental health problems, more stress, and more illness as a result of loss of jobs. ${ }^{30-32}$ Generally, the financial crisis in Europe seemed to have had different effects on different health outcomes, with the most consistent evidence being that for suicides and poor mental health. ${ }^{33}$ Moreover, in a review of research of the impact of latest economic crisis on health, Suhrcke and Stuckler concluded that in high income countries, the population groups especially affected in economic terms (e.g. through layoffs) faced absolutely and/or relatively greater health risks than more affluent groups, possibly leading to widening health inequities. ${ }^{32}$ Even many years later, some countries are still experiencing the consequences.

In Sweden and in various countries in the Eurozone, the latest recession led to increased unemployment, especially among the youth. ${ }^{34}$ For instance, an interview survey involving around 12000 workplaces in Sweden predicted that unemployment would increase between 2009 and 2010. During 2008-2012, the country as a whole experienced a fall in GDP, an unusual increase in redundancy notices, and the loss of industrial jobs. ${ }^{34,35}$ The unemployment rate in Sweden among adults aged 16-64 increased from $3.7 \%$ in 2008 to $6.5 \%$ in 2012 ; the corresponding figures for young people aged $18-24$ were $5.2 \%$ in 2008 and $10.5 \%$ in $2012 .{ }^{36}$ Even by November 2016, the unemployment rate in Sweden was still $6 \%$ among adults aged $16-64$ and $6.9 \%$ among young people aged $18-24 .^{36}$

Gävleborg Region was one of the counties hardest affected by factory closures and layoffs, compared to other regions of the country. Among adults aged 16-64 in Gävle municipality (the capital of the region), the unemployment rate increased considerably during the period 2008-2012, from 5.9\% in 2008 (5.5\% in the whole county) to $10.8 \%$ in 2012 (9.6\% in the whole county). For those aged 18-24, the unemployment rate increased even more, from $9.1 \%$ in 2008 (9.9\% in the whole county) to $17.2 \%$ in 2012 $\left(17.2 \%\right.$ in the whole county). ${ }^{36}$ Still today, several years later, the municipality is struggling to reduce its unemployment rate. ${ }^{36}$

Many studies, across a variety of contexts (including Sweden) have investigated the impact of health and well-being during times of economic recession, often using quantitative methodology. 2,26,37,38 However, in Gävle municipality, no study to our knowledge has attempted to investigate how people affected by unemployment perceive their well-being after an episode of unemployment. This study therefore aimed to provide a deeper understanding of experiences of unemployment and perceptions of well-being among persons who involuntary lost their work during the recent economic recession in Gävle municipality.

\section{Materials and Methods}

\section{Study design and setting}

We used a qualitative approach to gain a deeper understanding of how involuntarily unemployed persons perceived their wellbeing; this was considered suitable, as it produces contextually richer data. ${ }^{39}$ The study was carried out in Gävle municipality, a city, which as described above was substantially affected by factory closures and layoffs, compared to other regions of the country.

\section{Study sample}

The study used a purposeful sampling strategy, with individuals selected in order to suit the research question and the specific needs of the study. ${ }^{40}$ The selection criteria for participation were: being 18 years of age or over, having become involuntarily unemployed during or after 2008, being registered at the employment agency in Gävle, living in Gävle municipality, and having been unemployed for at least six months.

Recruitment of participants was initiated by making contact with the unemployment agency in Gävle. Posters asking for participants were put up at the agency's premises, and the staff at the agency were asked to assist in the recruitment process by asking individuals whether they would be interested in participating. Of the 50 people who were asked or who volunteered their own interest in participation, 20 were either unable to be reached, had got a job, or cancelled their appointment several times. An additional 14 of those interested were found not to correspond to the inclusion criteria, resulting in a final study sample of 16 respondents.

The participants were eight women aged 40-61 and eight men aged 28-62 years. Thirteen of them were born in Sweden, and three in other countries; 13 had secondary education and three had university education; nine owned their homes, six lived in rented accommodation, and one was lodging with relatives; nine lived with a person who had a steady income, one had an ill partner, and six were single; nine had children living at home.

\section{Data collection and process}

Staff at the employment office provided contact details (email addresses and phone numbers) of the individuals who volunteered to participate in the study. All those who signed up were contacted by telephone and they were asked again, if they had the opportunity to participate in the study. The informants were invited to come to the University of Gävle, where facilities suitable for interviews had been booked. Those who were unable to come to the university were given the option of the interviewer coming to their home to 
conduct the interview, but the majority of the interviews took place at the university. The premises for the interviews both at the university and in the individuals' homes were perceived as adequate, and no problems related to the environment were seen to occur.

Prior to the interviews and after receiving information about the study background and objectives, respondents were told of their right to withdraw, were given assurances of confidentiality, and were asked to give their oral consent. The interviews were conducted by two different interviewers, and all interviews but one (in English) took place in Swedish. Each interview lasted between 40 and 70 minutes, and was digitally recorded by permission of the respondent. Data collection took place during autumn 2013 and spring 2014. The interviews were based on a semi-structured interview guide with thematic open-ended questions developed by the research team. The interview guide contained questions in different domains such as experiences of unemployment, mental and physical health, the prospects for a new job, family ties, social and practical support, financial situation, stigma, and access to services.

\section{Data analysis}

Thematic analysis, a type of analysis that searches for patterns and themes, was used as an analytical tool. Braun and Clarke ${ }^{41}$ have argued that thematic analysis gives a purely qualitative, detailed, and nuanced explanation of the data, and is flexible and independent of theory and epistemology in the sense that it can be used across a range of epistemological and theoretical approaches. ${ }^{41}$ It also gives a way to organise and derive meaningful themes reflecting the data, and provides rich and detailed information, while taking into account the complexity of the data. ${ }^{41}$

The analysis was performed in six steps: 1) transcription and reading of data, and listing of initial thoughts; 2) initial coding, and systematic compilation of relevant data for each code over the entire data; 3) searching for topics; 4) examination of themes and checking that they worked in relation to the extracted codes (level 1) and the entire data set (level 2);5) analysis, refinement, and naming of each theme; and 6) selection of examples of findings linked to the research question. ${ }^{42}$

\section{Ethical approval}

The study followed the ethical guidelines of the Swedish Research Council ${ }^{43}$ and was approved by the Regional Ethical Committee in Uppsala.

\section{Results}

The analysis revealed six different themes from the interviews: I) work as the basis for belonging, II) a changed financial situation impacting social life and consumption patterns, III) unemployment leading to isolation and loss of self-esteem, IV) unemployment, health and well-being, V) the importance of unemployment duration, and VI) the search to feel well. Overall, job loss was described by some respondents as a feeling of minor shock, not knowing what to do. They had to make the best of the situation, and the consequences depended on the support they had, their age, and their financial situation. One respondent explained:

It gets bad or even worse depending on the person actual conditions. It's tough from the beginning, and for those who are disadvantaged from the beginning it's even tougher. (Respondent 4)

The respondents' experiences revolved around the consequences of job loss, as well as their psychological and physical well-being, as described in the following themes.

\section{Work as the basis for belonging}

The respondents described work as very important part of human identity in the sense that work was deeply ingrained in society and it was necessary to have a job in order to fulfil the role of a good person.

You can feel sometimes, as soon as you enter a larger context, meet new people, you're asked: 'Hi, what's your name?' The next question is what you do for a living. [...] When you're out with new people who don't know you, this question really feels sad, since that's what identity is all about. (Respondent 16)

Several of the respondents perceived work as the basis for belonging and dignity as a human being or as one woman expressed it:

I belong to nothing. When you have a job, you belong to something. You're included in something. But now I'm not that. Now I'm just something being tossed around somewhere. (Respondent 7)

Another woman expressed her feelings on dignity as:

I feel that people who work or have a place to work, they seem - they feel much more secure in life. I talk to people, no problem. But inside I feel that they are higher class than me. It's just my feeling. I don't want to show it. But in any case it's on the inside. (Respondent 11)

The informants also spoke about work as the aspect of life that gives structure and security:

Work means security, the feeling that you are safe, that you have a role in life. You are a part of life somehow. Now you are not, you are just a side spectator somehow. (Respondent 7).

Work means better routines, a better social network or social engagement - meeting people. You also have more pressure on you. (Respondent 4)

\section{A changed financial situation impacting social life and consumption patterns}

The respondents described a poorer financial situation as tough to deal with and as creating worry, stress, and insecurity. This in itself contributed to feelings of greater alienation and inadequacy. The consequences could depend on whether or not one was the sole breadwinner.

It's tough mentally, to constantly keep in mind, that the ketchup bottle is cheaper there [...]. Powerlessness, of not being able to influence your own situation [...]. Financial matters are stressful, since I have to spend so much time on them. (Respondent 13)

Psychologically you want to contribute something to the family, and although we have managed, because my partner has a good job, you still feel that you're not contributing anything. If you're going on holiday, she's the one who pays for it - and things like that can be stressful over the long term. (Respondent 3).

Due to their unemployment situation, respondents felt that could not follow social patterns and behaviours in their social environment. The lack of financial resources affected their ability to socialize and seek services (e.g. visit a doctor).

I've had to cut down on my leisure activities [...]. It's not a good thing to hesitate because it costs 300 crowns to go to the doctor. So if it's not really bad, you don't do it. (Respondent 5)

The respondents also spoke about not being able to buy what they wanted, not being able to go to the cinema with others, and not travelling like everyone else, as they used to do before. 
You have to be careful with money. You can't buy what you want. New glasses - and you have to think twice whether to take the car, the bus, or the bicycle. You can't allow yourself things like clothes, anything out of the ordinary (Respondent 15)

I can't plan for travel or anything like that. I need to think twice about buying clothes [...] buy good and comfortable shoes if you have problems with your feet, since they are expensive. Then you have to wait until the shoes are on sale. You are affected all the time, your entire life is affected. (Respondent 7)

\section{Unemployment leading to isolation and loss of self- esteem}

As consequences of all the above emotions, the respondents expressed isolation and alienation.

You're supposed to, and you look for a job and so on, but you don't socialize with anyone, but - I don't know, you've got access to a computer at home, so you don't go to the employment agency to sit and talk with anyone there either, instead you go home and sit down. So maybe you get a bit closed in. (Respondent 3)

Isolation reinforced emotions of worthlessness and shame. This in turn reduced the chances to establish new contacts and find new routes that could lead to a job.

You get low pretty fast. It only takes a week or so, and then you reach the bottom. You can become shy. And it goes faster than you think. I myself was surprised that it took no time. You lose selfesteem, if you ever had it, you lose it. You aren't worth anything. (Respondent 7)

\section{Unemployment, health and well-being}

The respondents' unemployment situation triggered feelings of hopelessness and fear of not getting a new job, which in turn affected their physical well-being (e.g. in terms of sleeping problems and progressive pain).

Much anxiety, difficulty sleeping. Should I say, perhaps too many nightmares that you're out looking for jobs at night and end up in different situations, you wake up and can't get back to sleep. I think, mainly it's this psychological part that affects me physically in that I sleep badly, and worries make you tired. Sometimes a little dejected. (Respondent 6)

So it's really been tough [...] I can imagine that this thing with the backache became a psychological side effect after the whole thing. When you sort of - when it turns out as hopelessness and when you don't get a new job, or don't get a job at all. So I think there's not only a physical injury, but they go hand in hand with each other. (Respondent 8)

\section{The importance of unemployment duration}

Even if the respondents initially saw unemployment as positive or had confidence that things would be fine, as time went by their negative emotions increased in the form of hopelessness and uncertainty for the future.

Yes, in the beginning it went well. It was more like a vacation. And financially it was no problem in the beginning. But then it feels a bit hopeless when you're trying to find a job - and even this internship I had, I was virtually promised that I'd get a summer job a year ago, not even that became true. Right now it just feels like waiting for the time to pass. Of course, it affects you a lot mentally. Wherever I am, it's just like you're waiting for something else to happen, and this belief that you'd get a job, you've almost given that up. (Respondent 10)
Some respondents also felt that as time went by, the duration of their unemployment had an effect on their ability to get a new job.

I don't experience it, as some say, that for every passing day you get closer to a job. Sometimes it feels that every day that passes, I get further away from it. And then it makes you feel worse and worse. (Respondent 6)

\section{The search to feel well}

Activities, structure, and affiliation in other contexts had become very important for the respondents' mental well-being. They perceived exercise and other activities to give meaning and hope, and felt that having a routine contributed to a stronger sense of purpose. In addition, the respondents saw other activities as their best coping resource against poor mental health as well as an important pathway to potential reintegration into the job market.

I try to divide and have a certain structure to the days, so I try to train; running, exercise, cycling, and so on. To have this physical part, so you're doing something rather than just sitting around at home. (Respondent 1)

Support from family and society was also mentioned as an important ingredient for mental well-being. The respondents mostly reported getting support from family and friends.

I talk a lot with the family. I've got a lot of support from my family in such a way [...] my parents and my siblings in general. (Respondent 12)

Some respondents emphasised the importance of support from the employment office and from the union, while others were deeply dissatisfied with this support or had not got any support at all.

The support through the employment service, I think that's extremely bad, if not completely absent. But I've had the privilege that the companies I've worked for have been connected to the Security Council. And there the commitment has been very great, and the social part as well, they've done very well. (Respondent 4)

\section{Discussion}

This study sought to provide a deeper understanding of how involuntarily unemployed persons living in Gävle municipality perceived their well-being during the most recent economic recession. The study found that the respondents perceived work as the basis for belonging, and loss of work affected their social life and consumption patterns due to changes in their financial situation. Moreover, the respondents expressed feelings of isolation which in turn reinforced their loss of self-esteem, and psychological symptoms such as feelings of hopelessness affected their physical wellbeing. Finally, longer duration of unemployment increased the respondents' negative emotions; and the respondents reported that activities, structure, and affiliation in contexts other than work were their coping strategies against poor mental well-being.

Our respondents expressed the importance of work for the human identity, and how without work they belonged to nothing due to loss of structure and security. In addition, they saw poor finances as a source of stress and insecurity, as this had substantial effects on their social life with family and friends. This is consistent with the findings of another qualitative study by Giuntoli et $a l .{ }^{2}$ which explored the impact of involuntary unemployment on everyday life and mental well-being in the UK during a time of economic recession. For instance, they found that their participants often talked about financial strain as a source of stress associated 
with the experience of unemployment, loss of time structure and routine, and loss of social role as part of the impact unemployment had on their everyday life. ${ }^{2}$ Moreover, our findings have similarities with the finding by Björklund et al. ${ }^{22}$ of feelings of exclusion from society among Finnish men.

Sweden is a welfare state that offers universal social protection. Welfare services for the unemployed entail unemployment benefits for the insured and need-tested social assistance for those not covered by insurance through previous employment. In this study, all respondents were registered in the unemployment agency, and received unemployment benefits. However, we did not ask if whether participants also received social assistance. Nevertheless, studies carried out elsewhere found that shame and stigma often were associated with receiving social welfare benefits. ${ }^{44,45}$ The findings in this study are also in line with the theory of $\mathrm{Jahoda}^{4}$, which argues that besides income, employment has many non-economic benefits, such as social status, identity, social contacts, structured time, collective aims, and activity. In addition, Nordenmark et al. ${ }^{1}$ have suggested that both the psychological and economic aspects of employment are important and central for mental well-being, and could affect unemployed persons in different ways. Results of this study did not detect very clear gender differences in the way respondents experienced their physical and psychological well-being. However, other studies have found gender differences regarding well-being and unemployment. ${ }^{46,47}$ For instance, findings from European social survey 2004 showed that one of the main factors affecting subjective well-being was having a job. In addition, the effect was greater for men than for women and that women could benefit from the jobs of their partners whereas men did not. ${ }^{47}$

The psychological consequences of unemployment have been reported mainly from quantitative research, which has consistently shown that loss of work and changes in one's financial situation are associated with decreased mental health. ${ }^{18,48-50}$ For instance, in a meta-analysis of 237 cross-sectional and 87 longitudinal studies, Paul \& Moser revealed that compared to their employed counterparts, unemployed persons had more symptoms of reduced wellbeing and distress. ${ }^{48}$ Furthermore, the study supported the evidence that unemployment is not only associated with, but also causes reduced mental health. ${ }^{48}$ In our study, the participants described how unemployment led to loss of self-esteem and isolation, which in turn created feelings of worthlessness. Our respondents perceived that as time went by they experienced a heightened sense of hopelessness, which in turn affected their physical wellbeing (e.g. in terms of sleeping difficulties and progressive pain).

The available research suggests that social capital, defined as participation in social activities and social networks, is beneficial for subjective well-being. ${ }^{51,52}$ The concept of social capital was not used in our study, but similarities can still be seen because our participants also experienced isolation (from colleagues, family, and friends), loss of self-esteem after job loss (which in their perceptions gave them structure, place of belonging and security), which together influenced their psychological well-being. However, using data from the German Socio-Economic Panel 1984-2004, Winkelmann ${ }^{53}$ found no evidence that social capital moderated the effect of unemployment on well-being. The impact of unemployment on people's mental health and well-being has also been found to be influenced by the use of coping strategies and the social or emotional support they might receive. ${ }^{2,49}$ For instance, Giuntoli et $a l{ }^{2}$ reported that coping strategies involving activities to reduce emotional stress were important in reducing the impact of unemployment on mental well-being and quality of life among men and women in Bradford, UK. Moreover, their participants underlined the importance of social support and access to services. We did not use the concept of coping strategies in the present study, but similarities can still be seen in that our participants expressed that activities, structure, and affiliation in other contexts were essential for them to feel good. Structured time use was also pointed out as an important factor for improved mental health in a meta-analysis carried out by McKee et al. ${ }^{49}$ Regarding support, the respondents in our study reported that most of their support came from family and friends, which stands in contrast to their general dissatisfaction with the little or no support received from the employment office.

\section{Strengths and limitations}

This study focuses on the experiences of well-being (rather than just health) among people who lost their job because of the most recent economic recession. In addition there was a great variety in age, family situation, housing, financial situation, and level of education among the participants, representing diverse experiences of unemployment. However, the study only included one municipality and a small number of participants, thus the findings should be interpreted with caution. Moreover, as mentioned before, we didn't ask about welfare benefits, as economic benefits in Sweden are universal. However, in the contexts were such benefits do not exist it is more likely that poverty may occur.

\section{Conclusions}

After job loss, the respondents experienced feelings of loss of dignity and belonging as a human being. They also felt worry, insecurity, and stress due to their changed financial situation, which in turn led to isolation and loss of self -esteem. Social support and having other activities gave them structure and meaning. Although Sweden has a universal welfare system and generous benefits, our results indicate that unemployed people can still experience different types of stress that affect their health and well-being. The respondents' experiences can be informative in similar contexts and results warrant attention from decision makers to meet this group's needs with actions aimed to deal with issues of well-being and unemployment.

Correspondence: Anne-Sofie Hiswåls, Department of Health Science, MidSweden University, SE-851 70 Sundsvall, Sweden.

Tel.: +46-26-645096

E-mail: anne-sofie.hiswals@hig.se

Key words: Out of work, perceived wellbeing, qualitative approach, recession time.

Acknowledgements: The authors thank the unemployment agency in Gävle for helping with the recruitment of the study participants. In addition the authors thank all respondents for their participation in the study. The study was financed by the University of Gävle Internal Grant 2013-4.

Contributions: ASH and GM conceptualised the study. ASH wrote the first draft of the manuscript. All authors wrote, revised and edited the manuscript. All the authors read and approved the final version of the manuscript.

Conflict of interest: the authorsdeclare no potential conflict of interest.

Received for publication:12 May 2017.

Accepted for publication: 11 September 2017.

CC Copyright A.-S. Hiswåls et al., 2017

Licensee PAGEPress, Italy

Journal of Public Health Research 2017;6:995

doi:10.4081/jphr.2017.995

This work is licensed under a Creative Commons Attribution NonCommercial 4.0 License (CC BY-NC 4.0). 


\section{References}

1. Nordenmark M, Strandh M. Towards a sociological understanding of mental well-being among the unemployed: the role of economic and psychosocial factors. Sociology 1999;33:57797.

2. Giuntoli G, South J, Whilte J. The impact of involuntary unemployment on mental well-being at a time of economic recession and the role of community interventions to strengthen people's resilience. Paper presented at the Social Policy Conference; 2011 July 4-6; Lincoln, UK

3. Giuntoli G, Hughes S, Karban K, South J. Towards a middlerange theory of mental health and well-being effects of employment transitions: Findings from a qualitative study on unemployment during the 2009-2010 economic recession. Health 2015;19:389-412.

4. Jahoda M. The impact of unemployment in the 1930's and the 1970's. Bull Brit Psychol Soc 1979;32:309-14.

5. Jahoda M. Employment and unemployment: a social-psychological analysis. CUP Archive, 1982.

6. Huffman AH, Culbertson SS, Wayment HA, Irving LH. Resource replacement and psychological well-being during unemployment: the role of family support. J Vocat Behav 2015;89:74-82.

7. Eliason M, Storrie D. Does job loss shorten life? J Hum Resour 2009;44:277-302.

8. Sullivan D, Von Wachter T. Job displacement and mortality: an analysis using administrative data. Quart J Econ. 2009; 124: 1265-1306.

9. Browning M, Dano AM, Heinesen E. Job displacement and stress-related health outcomes. Health Econ 2006;15:1061-75.

10. Salm M. Does job loss cause ill health? Health Econ 2009;18:1075-89.

11. Hammarström A, Gustafsson PE, Strandh M, et al. It's no surprise! Men are not hit more than women by the health consequences of unemployment in the Northern Swedish Cohort. Scand J Public Health 2011;39:187-93.

12. Janlert U. Unemployment as a disease and diseases of the unemployed. Scand J Work Environ Health 1997:79-83.

13. Montgomery SM, Cook DG, Bartley MJ, Wadsworth MEJ. Unemployment, cigarette smoking, alcohol consumption and body weight in young British men. Eur J Public Health 1998;8:21-7.

14. Mossakowski KN. Is the duration of poverty and unemployment a risk factor for heavy drinking? Soc Sci Med 2008;67:947-55.

15. Reine I, Novo M, Hammarström A. Does the association between ill health and unemployment differ between young people and adults? Results from a 14-year follow-up study with a focus on psychological health and smoking. Public Health 2004; 118:337-45.

16. Virtanen P, Janlert U, Hammarström A. Health status and health behaviour as predictors of the occurrence of unemployment and prolonged unemployment. Public Health 2013;127:46-52.

17. Artazcoz L, Benach J, Borrell C, et al. Unemployment and mental health: understanding the interactions among gender, family roles, and social class. Am J Public Health 2004;94:828.

18. Backhans MC, Hemmingsson T. Unemployment and mental health: who is (not) affected?. Eur J Public Health 2011;22:429-33.

19. Luo J, Qu Z, Rocket L, Zhang X. Employment status and selfrated health in north-western China. Public Health
2009; 124:174-9

20. Sun S, Chen J, Johannesson M, Kind P, Burström K. Subjective well-being and its association with subjective health status, age, sex, region, and socio-economic characteristics in a Chinese population study. J Happ Studies 2016;17:833-73.

21. Kira M, Klehe U. Self-definition threats and potential for growth among mature-aged job-loss victims. Hum Resour Managem Rev 2016;26:242-59.

22. Björklund O, Söderlund M, Nyström L, Häggström E. Unemployment and health: experiences narrated by young finnish men. Am J Mens Health 2015;9:76-85.

23. Patton W, Donohue R. Coping with long-term unemployment. J Comm App Social Psych 1998;8:331-43.

24. Adler A, Seligman ME. Using wellbeing for public policy: theory, measurement, and recommendations. Int $\mathrm{J}$ Wellbeing 2016;6.

25. Bartels M. Genetics of wellbeing and its components satisfaction with life, happiness, and quality of life: a review and metaanalysis of heritability studies. Behav Genet 2015;45:137-56.

26 Ohls C. A qualitative study exploring matters of ill-being and well-being in Norwegian activation policy. Soc Pol Society 2016:1-14.

27. Deeming C. Addressing the social determinants of subjective wellbeing: the latest challenge for social policy. J Soc Policy 2013;42:541-65.

28. Layard R. Economics. Measuring subjective well-being. Science 2010;327:534-35.

29. Giatti L, Barreto SM, César CC. Unemployment and self-rated health: neighborhood influence. Soc Sci Med 2010;71:815-23.

30. World Health Organization. The financial crisis and global health: report of a high-level consultation, Geneva, Switzerland, 19 January 2009.

31 Stuckler D, Basu S, Suhrcke M, et al. The public health effect of economic crises and alternative policy responses in Europe: an empirical analysis. Lancet 2009;374:315-23.

32. Suhrcke M, Stuckler D. Will the recession be bad for our health? It depends. Soc Sci Med 2012;74:647-53.

33. Parmar D, Stavropoulou C, Ioannidis JP. Health outcomes during the 2008 financial crisis in Europe: systematic literature review. BMJ 2016;354:i4588.

34. Arbetsförmedlingen. Arbetsmarknadsutsikterna för år 2009 och 2010. Sysselsättningen minskar i alla län [in Swedish] Swedish labour market outlook- for 2009 and 2010 [Summary in English], [cited 2017 January 4]. Available from: https://www.arbetsformedlingen.se/Om-oss/Statistik-och-publikationer/Prognoser.html

35. Arbetsförmedlingen. Varselstatistik per län: Antal personer berörda av varsel om uppsägning 1992-2015, [cited 2017 January 4]. Available from: http://www.arbetsformedlingen.se/Om-oss/Statistik-prognoser/Tidigare-statistik.html

36. Arbetsförmedlingen. [homepage on internet]. Öppet arbetslösa och sökande i program med aktivitetsstöd andelar av befolkningen 1996 -2015, [cited 2017 January 4]. Available from: http://www.arbetsformedlingen.se/Om-oss/Statistikprognoser/Tidigare-statistik.html

37. Urbanos-Garrido RM, Lopez-Valcarcel BG. The influence of the economic crisis on the association between unemployment and health: an empirical analysis for Spain. Eur J Health Econ 2015;16:175-84.

38. Drydakis N. The effect of unemployment on self-reported health and mental health in Greece from 2008 to 2013: a longitudinal study before and during the financial crisis. Soc Sci 
Med 2015;128:43.

39. Mack N, Woodsong C, MacQueen KM, Guest G, Namey E. Qualitative research methods: a data collector`s field guide. 2005.

40. John W. Creswell. Qualitative inquiry and research design: choosing among five approaches: Sage; 2012.

41. Braun V, Clarke V. Using thematic analysis in psychology. Qual Res Psychol 2006;3:77-101.

42. Vaismoradi M, Turunen H, Bondas T. Content analysis and thematic analysis: implications for conducting a qualitative descriptive study. Nurs Health Sci 2013;15:398-405.

43. Codex.vr.se [homepage on internet]. CODEX - regler och riktlinjer för forskning. Humanistisk och samhällsvetenskaplig forskning [updated 2016 October 9; cited 2017 January 4]. Available from: http://codex.vr.se/forskninghumsam.shtml

44. Walker R, Kyomuhendo GB, Chase E, et al. Poverty in global perspective: is shame a common denominator? J Soc Policy 2013;42:215-33.

45. Baumberg B. The stigma of claiming benefits: a quantitative study. J Soc Policy 2016;45:181-99.
46. Knabe A, Schöb R, Weimann J. Partnership, gender, and the well-being cost of unemployment. Soc Indicators Res 2016;129:1255-75.

47. Van der Meer, Peter H. Gender, unemployment and subjective well-being: why being unemployed is worse for men than for women. Soc Indicators Res 2014;115:23-44.

48. Paul KI, Moser K. Unemployment impairs mental health: meta-analyses. J Vocat Behav 2009;74:264-82.

49. McKee-Ryan F, Song Z, Wanberg CR, Kinicki AJ. Psychological and physical well-being during unemployment: a meta-analytic study. J Appl Psychol 2005;90:53.

50. Price RH, Friedland DS, Vinokur AD. Job loss: hard times and eroded identity. In: Perspectives on loss: a sourcebook 1998: 303-316.

51. Helliwell JF, Putnam RD. The social context of well-being. Philos Trans R Soc Lond B Biol Sci 2004:1435-46.

52. Groot W, Brink H, Praag B. The compensating income variation of social capital. Soc Indicators Res 2007;82:189.

53. Winkelmann R. Unemployment, social capital, and subjective well-being. J Happ Studies 2009;10:421-30. 